\title{
Shaping the Face and the Voice of TMS: You Can Help to Ensure All Demographics are Represented
}

\author{
Elizabeth A. Holm
}

At this very moment, you are reading $J O M$ - and you're not the only one. Every month, JOM is mailed to each TMS member, with electronic access for student members. Some members read it cover to cover, and others skim it for topics of interest, whether news, member information, or technical articles. Surveys perennially rank JOM as one of the top TMS member benefits, and JOM's impact factor exceeds many materials technical journals. TMS members read $J O M$.

TMS members also write $J O M$. They submit technical papers, news releases, interviews, job openings, letters to the editor, obituaries, and perspectives like this one. JOM provides a way for TMS members to connect with each other. $J O M$ is the voice of TMS.

As our voice, JOM should reflect our community: the diverse membership of TMS. Unfortunately, that is not always the case. A few months ago, I opened $J O M$ to find that not a single contributor was a woman, even though the TMS professional membership is now about $10 \%$ female. Likewise, contributions by our international members do not reflect their member numbers. Younger members are also underrepresented. Overall, contributors to JOM better reflect our traditional membership than our current membership.

Interestingly, a number of other member benefits show the same imbalance. The TMS Awards program is one of the most visible, public faces of TMS. People who may not otherwise be involved with TMS - people like your boss - take note of our prestigious awards. Yet in the 89 years since the establishment of our first society-level award, women have won TMS's pinnacle technical awards only twice, and only five women are TMS Fellows. At least in recent times, the problem isn't discrimination during the selection process; it is that women are not nominated for awards at a rate commensurate with their population. The result is that our public face does not match the actual faces of our membership.

All of this is not surprising, because we spend our time in school learning our job function-how to do the work of a materials scientist or engineer. What we don't always learn is our professional function - how to be an effective member of the materials community. It takes some time-and good mentoring - to realize the networking value of the activities promoted by TMS. My goal in this column is to practice remote mentoring and encourage you all to take advantage of these important member benefits.

We'll start with JOM. JOM is your venue to reach customers, colleagues and friends in a variety of ways. Submit a news tip on a scientific or technical advance. Write a column on a policy issue that impacts your industry. Introduce your research in a technical paper. Inform the community about a member's accomplishment, award, or transition. Make sure that your voice is one of the voices of TMS.

Award nominations provide a way for TMS members to recognize their outstanding colleagues both inside and outside the TMS community. The process is simple and starts with individual TMS members like you. Identify an outstanding colleague, whether an eminent researcher, a successful engineer, or an influential mentor. Fill out a nomination form, attach the nominee's $\mathrm{CV}$, and solicit several supporting letters from colleagues. Give the awards committees the best and brightest, and they will do the rest. Help shape the face of TMS.

You'll find benefits that help you in the workplace and beyond. You may identify a new customer - receive input from a colleague - inform a friend - influence a policy maker - reward a role model - shape the perception of our profession. You'll be participating fully in your professional community and receiving the maximum value from your network of peers.

In the not-too-distant future, I look forward to opening an issue of JOM and finding submissions from TMS members in every demographic. Even better, one of the articles will list the TMS award recipients for the year, diverse in gender, culture, and job sector. Then we will see the true face and hear the true voice of our Society.

Here are some practical details to get you started: For ideas, questions, and procedures for $J O M$ submissions, contact the JOM editor, Maureen Byko (mbyko@tms.org). The JOM website (jom.tms.org) also has helpful information. For a list of TMS-sponsored awards, go to the Awards website ( $w w w$ .tms.org/Society/TMSawards.aspx); the nomination materials are located at www.tms.org/society/TMSawards Application.aspx and www.tms.org Society/nomination-form.pdf. Finally, to learn other ways to get involved, contact me or any member of the TMS Board of Directors. You can find a list of Board members at members.tms.org/admin .html?divisions/bod.asp, and our contact information is in the Member Directory (members.tms.org) - another valuable member benefit!

Elizabeth A. Holm, incoming TMS Vice President, is a Distinguished Member of the Technical Staff at Sandia National Laboratories in Albuquerque, New Mexico. 